\title{
INFLUÊNCIA DO USO DE PRÓTESE DENTÁRIA NO APORTE NUTRICIONAL DA POPULAÇÃO GERIÁTRICA RURAL DE TRÊS DISTRITOS DA REGIÃO CENTRO DE PORTUGAL
}

INFLUENCE OF THE USE OF DENTAL PROSTHESIS ON THE NUTRITIONAL INTAKE OF THE RURAL GERIATRIC POPULATION OF THREE DISTRICTS OF THE CENTRAL REGION OF PORTUGAL INFLUENCIA DE LA UTILIZACIÓN DE PRÓTESIS DENTAL EN LA INGESTA NUTRICIONAL DE LA POBLACIÓN GERIÁTRICA RURAL DE TRES DISTRITOS DE LA REGIÓN CENTRAL DE PORTUGAL

\author{
Joana Dias* (joana.dias.96@hotmail.com) \\ António Fernandes** (toze@ipb.pt) \\ Fátima Viana*** (mariaviana@ipb.pt)
}

\section{RESUMO}

Este estudo tem como objetivos averiguar em que medida o uso de prótese dentária influencia o aporte nutricional dos idosos e perceber quais os indicadores sociodemográficos que condicionam a procura de tratamento odontológico, bem como o uso e tipo de prótese dentária. Metodologicamente procedeu-se a uma avaliação cognitiva, um questionário de identificação do idoso, aplicação da ferramenta Geriatric Oral Health Assessment Indexe uma anamnese alimentar, numa amostra de 400 idosos de três distritos portugueses. Verificou-se uma correlação $(p=0,006)$ entre o nível de escolaridade e periodicidade de idas ao dentista, e ainda uma associação entre o género e uso de prótese dentária $(p=0,000)$, entre o uso de prótese e nível de escolaridade $(p=0,007)$ e entre o tipo de prótese dentária e rendimento $(p<0,05)$. Constataram-se diferenças, estatisticamente significativas, no aporte diário de ferro $(p=0,014)$ e fósforo $(p=0,042)$ nos indivíduos portadores e não portadores de prótese dentária e, ainda, diferenças no aporte diário de proteína total, vitamina $A$, carotenos, $\alpha$-tocoferol, cinza, magnésio $(p<0,05)$, quando os diferentes tipos de prótese dentária foram considerados. Conclui-se que o nível de escolaridade e género condicionam a procura de tratamento odontológico. O uso de prótese condiciona o aporte nutricional diário de ferro e fósforo.

Palavras Chave: idoso, prótese dentária, aporte nutricional.

\section{ABSTRACT}

This study aims to investigate the extent to which the use of dental prosthesis influences the nutritional intake of the elderly, and to understand the sociodemographic indicators that condition the demand for dental treatment, as well as the use and type of dental prosthesis. Methodologically we proceeded to a cognitive evaluation, a questionnaire identifying the elderly, application of the 
Geriatric Oral Health Assessment Index tool and a food anamnesis were carried out in a sample of 400 elderly people from three Portuguese districts. There was a correlation $(p=0.006)$ between the level of schooling and the periodicity of dental visits, as well as an association between gender and use of dental prosthesis $(p=0.000)$, between prosthesis use and schooling level $(p=0.007)$ and between the type of dental prosthesis and yield $(p<0.05)$. Statistically significant differences were observed in the daily intake of iron $(p=0.014)$ and phosphor $(p=0.042)$ in individuals with and without dental prosthesis, and differences in the daily intake of total protein, vitamin $A$, carotenes, $\alpha-$ tocopherol and magnesium $(p<0.05)$ when compared to different types of dental prostheses. It is concluded that the level of education and gender condition the demand for dental treatment. The use of prosthesis affects the daily nutritional supply of iron and phosphorus.

Keywords: elderly, dental prosthesis, nutritional intake.

\section{RESUMEN}

Este estudio tiene como objetivos determinar en qué medida el uso de prótesis dentales influye en el aporte nutricional de los ancianos y percibir qué indicadores sociodemográficos influyen en la demanda de tratamiento odontológico/dental, así como el uso y el tipo de prótesis dentales. Metodológicamente se realizó na evaluación cognitiva, un cuestionario de para identificar a los ancianos, la aplicación de la herramienta Geriatric Oral Health Assessment Index y una anamnesis alimentaria, en una muestra de 400 ancianos de tres distritos portugueses. Se verificó una correlación $(p=0,006)$ entre el nivel de educación y frecuencia de visitas al dentista, así como una asociación entre el género y el uso de prótesis dentales $(p=0,000)$, entre el uso de prótesis y nivel de de educación $(p=0,007)$ y entre el tipo de prótesis dental y rendimiento $(p<0,05)$. Se observaron diferencias estadísticamente significativas en el aporte diario de hierro $(p=0,014)$ y fosforo $(p=0,042)$ en los individuos portadores y no portadores de prótesis dentales, y aún diferencias en el aporte diario de proteína total, vitamina A, carotenos, $\alpha$-tocoferol, gris, magnesio $(p<0,05)$, cuando se comparan los diferentes tipos de prótesis dentales. Se concluye que el nivel de estudios y el género condicionan la demanda de tratamiento dental. El uso de prótesis afecta el suministro nutricional diario de hierro y fósforo.

Palabras clave: ancianos, prótesis dentale, aporte nutricional.

*Escola Superior de Saúde, Instituto Politécnico de Bragança.

**Departamento de Ciências Sociais e Exatas, Escola Superior Agrária, Instituto Politécnico de Bragança. Centro de Investigação de Montanha, Instituto Politécnico de Bragança.

***Departamento de Tecnologias de Diagnóstico e Terapêutica, Escola Superior de Saúde do Instituto Politécnico de Bragança. Nutricionista no Centro Hospitalar de Vila Nova de Gaia/Espinho EPE.

Submitted: $8^{\text {th }}$ July 2019

Accepted: $13^{\text {th }}$ July 2020 


\section{INTRODUÇÃO}

A preocupação cada vez mais premente com a saúde, em concreto a saúde que depende da alimentação da população portuguesa é uma constante. Em paralelo e, dado o envelhecimento da população a nível mundial, a saúde dos idosos e a sua relação com a desnutrição e ou obesidade é cada vez mais estudada. De acordo com a Organização Mundial da Saúde, idoso é definido, segundo a sua idade cronológica, como o indivíduo com idade igual ou superior a 60 anos, nos países em desenvolvimento, e com 65 anos ou mais nos países desenvolvidos (OMS, 2015). Segundo Papila e Feldman (2013), idosos jovens referem-se aos indivíduos de 65 a 74 anos, idosos velhos de 75 a 84 anos e idosos mais velhos de 85 ou mais anos de idade.

Nas últimas décadas verifica-se um rápido envelhecimento mundial, acompanhado por um aumento da esperança média de vida. Portugal também acompanha esta tendência de envelhecimento, sendo considerado, entre os 28 Estados Membros da União Europeia (EMUE), o 5o país com maior população idosa (Cunha, 2013; INE, 2015). O índice de envelhecimento para os 28 EMUE, em 2013, era mais elevado na Alemanha (159 idosos), seguido da Itália (154 idosos), Bulgária (142 idosos), Grécia (140 idosos) e Portugal (136 idosos). Ao longo dos anos, com o declínio da natalidade e o aumento da longevidade, verificou-se, na população portuguesa, um decréscimo da população jovem ( 0 a 14 anos de idade) e da população em idade ativa ( 15 a 64 anos de idade) e, em simultâneo, um aumento da população idosa (INE, 2015).

Este aumento do envelhecimento populacional constituiu um dos maiores desafios para a saúde pública no que se refere à saúde oral (Magalhães, 2011; Vial, 2017). O envelhecimento fisiológico é frequentemente complementado por diversas doenças crónicas, polifarmácia, fragilidade e a perda de autonomia, sendo a população com maior predisposição a infeções orais devido a doenças sistémicas relacionadas com a idade e associadas a outros problemas, interferindo e limitando as atividades diárias, destacando as repercussões das alterações nos domínios funcionais, psicológicos e sociais (Vial, 2017; Sousa, 2016). Neste sentido, a saúde oral é influenciada pelo estilo de vida (alimentação, higiene oral, tabagismo e alcoolismo), o acesso a serviços especializados (condições económicas, políticas e organização do sistema de saúde do país) e por fatores biológicos inerentes ao indivíduo (Sousa, 2016).

O edentulismo, ou seja, a ausência parcial ou total de dentes, é o reflexo da falta de prevenção, informação e, consequentemente, falta de cuidados de higiene oral, sendo designado como um fenómeno natural do envelhecimento, uma vez que afeta, principalmente, a população geriátrica (Agostinho, Campos \& Silveira, 2015). Esta perda de dentes pode estar associada à idade, educação, situação financeira, classe social e hábitos tabágicos, limitando as funções diretamente relacionadas com a manutenção da qualidade de vida (Cunha, 2013; Agostinho et al, 2015).

A Qualidade de Vida dos indivíduos é influenciada pela condição de saúde, inclusive, a saúde oral (OHrQoL - Oral Health Related Quality of Life), uma vez que, uma insalubridade oral conduz a restrições físicas e psicológicas influenciando diretamente a alimentação, fala, locomoção, convívio social e autoestima. Para a avaliação da OHrQoL, devem ser analisados quatro aspetos: dor e desconforto, aspetos funcionais relativos à capacidade de mastigação e deglutição, fonação e pronúncia, aspetos psicológicos referentes à aparência e autoestima, bem como os aspetos sociais, refletindo interação social e comunicação com as pessoas (Sousa, 2016). Oral Health Inventory Profile (OHIP), Oral Impacts on Daily Performance (OIDP) e Geriatric Oral Health Assessment Index (GOHAI) são exemplos de instrumentos 
desenvolvidos para avaliar a OHrQoL. O GOHA/ mostrou-se sensível à prestação de atendimento odontológico, sendo o mais adequado e eficaz para detetar problemas relacionados com a saúde oral do que outro questionário amplamente utilizado na $O H R Q O L$ (Pillai, Mathur, Jain, Shah, Kalra \& Kumar, 2015).

É uma saúde oral comprometida, ou seja, a ausência parcial ou total de dentes, a presença de lesões, infeções na mucosa e o uso de próteses inadequadas, conduz a uma comprometida qualidade da alimentação ingerida pelos indivíduos. Ainda neste contexto, assiste-se a uma diminuição da eficiência mastigatória conduzindo, por sua vez, a um impacto negativo nos aspetos nutricionais qualitativos e quantitativos, a uma rejeição alimentar, desencadeando assim um processo de desnutrição (com prevalência de 0-10\% para idosos independentes e 50\% para pacientes geriátricos agudos ou hospitalizados) (Magalhães, 2011; Dias, 2012; Mckenna, Allen, Flynn, O'Mahony, Damata \& Cronin, 2012; Cunha, 2013).

Com uma saúde oral debilitada, os idosos têm maior tendência de adaptar a dieta à sua condição dentária, fazendo com que haja o menor desconforto aquando da ingestão alimentar, ou seja, alterando a textura dos géneros alimentícios, aumentando o consumo de alimentos macios e fáceis de digerir, culminando, muitas das vezes, numa redução de apetite, como consequência da perda de prazer na alimentação, originando uma dieta desequilibrada e diminuição da ingestão. Assim a diminuição e/ou ausência de determinados alimentos, com uma textura mais fibrosa e, por isso, mais difíceis de mastigar, conduz a um défice nutricional, que pode resultar num aumento de problemas de saúde (Magalhães, 2011; Dias, 2012; Cunha, 2013; Toniazzo et al, 2018).

A presença de dentes, o número de dentes funcionais, bem como o uso de prótese podem afetar a eficiência e capacidade mastigatória e, portanto, influenciar a escolha e preparação dos alimentos (Magalhães, 2011). Cerca de $25 \%$ dos idosos apenas apresentam dentes num maxilar, portanto colocam prótese dentária parcial, o que pode acarretar problemas na estabilidade. Atualmente, os idosos conseguem permanecer com os seus dentes naturais, verificando-se o aumento dos tratamentos odontológicos restauradores e, portanto, em vez de se extraírem todos os dentes, o objetivo é manter o maior número de dentes naturais possíveis e apenas em último recurso implementar próteses dentárias (Muller, Naharro \& Carlsson, 2007).

A reabilitação protética, desde que seja adequada, transcende à simples reposição de dentes, uma vez que permite ao idoso melhorar a sua dimensão psicossocial e manter a sua saúde geral, oferecendo uma melhoria na capacidade mastigatória e, consequentemente, na ingestão alimentar, proporcionando um aporte nutricional mais adequado (Cunha, 2013). A prevalência do uso de prótese dentária em 2008 , era de $46,2 \%$, sendo que o seu uso ou não era, significativamente, distinto em relação à idade, ao estatuto socioeconómico, ao estilo de vida e à saúde no geral (Cunha, Santos, Costa, Pereira, Varanda \& Loureiro, 2014).

Desconhecem-se estudos portugueses que analisem a influência do estado da saúde oral, mais especificamente, o uso de prótese dentária na ingestão alimentar/aporte nutricional dos indivíduos. Neste sentido, tendo em conta esta relação mútua da saúde oral com o estado nutricional dos idosos descrita na literatura, este estudo tem como objetivos averiguar em que medida o uso de prótese dentária influencia os hábitos alimentares e, consequentemente, o aporte nutricional dos idosos, identificando quais os indicadores sociodemográficos que condicionam a procura de tratamento odontológico, bem como o uso e tipo de prótese dentária. 


\section{METODOLOGIA}

Para atingir os objetivos propostos utilizou-se um estudo transversal, analítico, observacional e quantitativo. A população estudada incluiu idosos dos distritos de Coimbra, Guarda e Viseu. A amostra foi selecionada a partir da população geriátrica rural destes três distritos, num total de 56147 indivíduos (INE, 2017). Desta população foi retirada uma amostra de 400 idosos. Trata-se de uma amostra representativa em termos quantitativos uma vez que o uso de uma calculadora de dimensão amostral disponível online (Raosoft, 2017) revelou que, numa margem de erro de 5\%, com um intervalo de confiança de $95 \%$, uma resposta de distribuição de 50\% necessitava-se no mínimo de 382 idosos. Esta amostra apresenta-se como não probabilística e acidental, visto que apenas participam no estudo os indivíduos que se encontram, no momento da recolha de dados. É também uma amostra de conveniência, uma vez que foi selecionada a partir de uma população acessível de acordo com a conveniência dos investigadores.

Os critérios de inclusão foram: idade igual ou superior a 65 anos, idosos de ambos os sexos, com capacidade de comunicação compreensiva e expressiva e que se alimentassem apenas por via oral. Os critérios de exclusão foram: idosos com trato gastrointestinal não funcionante, idosos que se alimentam por sonda ou via parentérica e idosos diagnosticados com alteração dos níveis de consciência.

A recolha de dados decorreu durante o mês de dezembro de 2017 e fevereiro de 2018, no domicílio dos idosos, onde foram colocadas, verbalmente, todas as perguntas inerentes ao questionário. Os investigadores iam identificados como finalista da licenciatura em Dietética e Nutrição e com um parecer escrito da orientadora para a realização do trabalho. Os investigadores foram previamente treinados relativamente à colocação das questões aos idosos, de modo a não existir discrepâncias nos dados recolhidos.

Foi entregue a cada idoso o Consentimento Informado, Livre e Esclarecido para participação na investigação de acordo com a declaração de Helsínquia e Convenção de Oviedo (Kong \& West, 2013), onde estavam discriminadas todas as informações relativas ao trabalho de investigação (em que consiste, qual a finalidade, métodos, financiamento e confidencialidade), com o intuito dos participantes ficarem totalmente esclarecidos acerca do presente estudo. Caso o participante fosse iletrado e, por esse motivo incapaz de assinar este consentimento, e na ausência de um familiar o assinar, os investigadores assinavam o documento. A participação no estudo foi inteiramente voluntária, pelo que, a qualquer momento, podiam recusar colaborar, sem que implicasse qualquer prejuízo direto ou indireto para o idoso. Todos os dados que foram fornecidos pelos participantes são totalmente confidenciais, sendo que apenas os investigadores têm acesso à informação.

Inicialmente realizou-se uma avaliação cognitiva para averiguar o estado mental do idoso e, se o mesmo respondesse acertadamente a todas as questões, procedia-se a um questionário contendo a identificação do idoso, as perguntas da ferramenta GOHAl (Geriatric Oral Health Assessment Index), que se encontra validada para a população portuguesa (Carvalho et al, 2013) e, uma entrevista de anamnese alimentar. Realizou-se um pré-teste do questionário de identificação do utente e da entrevista de anamnese alimentar do dia habitual em trinta idosos no distrito de Coimbra, Guarda e Viseu. Verificou-se que todos os idosos compreenderam as questões que foram elaboradas, não sendo necessário a reformulação dos instrumentos de recolha de dados. 
A avaliação inicial era composta por 4 questões: Idade, Data de nascimento, Lugar e Ano (Swain et al, 1997). O questionário era composto por cinco questões relacionadas com as variáveis sociodemográficas (idade, género, rendimento, nível de escolaridade, contexto habitacional), quatro questões relativas à saúde oral do idoso, (frequência de consultas dentárias, o uso de prótese, tipo de prótese dentária e remoção da prótese na hora da refeição) e por fim 12 questões relativas à ferramenta GOHA/ (Carvalho et al, 2013). Esta ferramenta é um questionário validado para a população geriátrica portuguesa, constituído por 12 itens, contendo três dimensões: física (padrão de mastigação, fala e deglutição), psicossocial (preocupações com a saúde oral, satisfação ou insatisfação com a aparência, autoconsciência sobre a saúde oral e evicção do contacto social) e dor ou desconforto (uso medicação para atenuar a dor ou desconforto relacionado com a cavidade oral) (Carvalho, Manso, Escoval, Salvador \& Nunes, 2013). Na entrevista de anamnese alimentar utilizou-se o recordatório 24 horas anteriores e questões relativas aos hábitos alimentares dos idosos.

Para efetuar a análise estatística dos dados recolhidos utilizou-se o programa SPSS (Statistical Package for the Social Sciences) versão 23 para Windows. O tratamento dos dados iniciou-se com a estatística descritiva com o intuito de caraterizar a amostra, recorrendo-se ao cálculo da distribuição das frequências nas variáveis nominais/ordinais e ao cálculo da média, desvio padrão, valor mínimo e máximo nas variáveis quantitativas (Maroco, 2003).

Para estudar a correlação entre a periodicidade de visitas ao dentista e os fatores sociodemográficos, medidos numa escala ordinal (rendimento, idade classes e nível de escolaridade), foi utilizado o teste de Spearman, que fornece o coeficiente de correlação linear (r), indicando o nível de intensidade da correlação entre as variáveis, oscilando entre os valores do intervalo $[-1,+1]$. Se $r=+1$ denomina-se como uma correlação positiva perfeita, $r$ $=-1$ uma correção negativa perfeita e $r=0$ não existe correlação entre as variáveis, sendo que quanto mais próximo o valor de r estiver de "1", mais forte é a correlação, quanto mais próximo o valor estiver de "0", mais fraca é a correlação entre as variáveis e se for igual a 1, existe uma correlação perfeita (Correia, 2003; Patrício, Loureiro \& Caramelo, 2015). A variável rendimento foi classificado segundo os IAIS (0-1IAS, 1-2IAS, 2-3IAS e 3IAS-4IAS, sendo que 1 IAS corresponde a $421 €$ ) e a idade classes em idosos jovens ( 65 a 74 anos), idosos velhos ( 75 a 84 anos) e idosos mais velhos (mais de 85 anos) (Papalia \& Feldman, 2013; Diário da República, 2017). O processo de decisão estatística tem por base o teste das hipóteses, hipótese nula $\left(\mathrm{H}_{0}\right)$ e alternativa $\left(\mathrm{H}_{1}\right)$, sendo $\mathrm{H}_{0}$ definida como: não há correlação, estatisticamente significativa, entre as variáveis e $\mathrm{H}_{1}$ como: há correlação, estatisticamente significativa, entre as variáveis (Maroco, 2003). Para estudar a relação entre as variáveis nominais dicotómicas (género e contexto habitacional) e periodicidade da frequência da consulta do dentista (variável ordinal) utilizou-se o teste Qui-Quadrado de Pearson, sempre que a regra prática se verificasse. A regra prática consiste na verificação das seguintes condições: $N>20$, todos as frequências esperadas superiores a superiores ou iguais a $5 \mathrm{em}$ pelo menos $80 \%$ das células da tabela de contingência. Em alternativa utilizou-se o teste Exato de Fisher (Maroco, 2003).

Utilizou-se, também, o teste de Qui-Quadrado de Pearson, para analisar a relação entre o uso de prótese e periodicidade de idas ao dentista, bem como a relação entre uso/tipo de prótese, fatores sociodemográficos (classes de idade, rendimento e nível de escolaridade) e modo de confeção das refeições principais. Caso se verificasse a violação da regra prática, recorria-se à técnica de simulação de Monte Carlo (Maroco, 2003). Para estudar a relação entre uso/tipo de prótese e fatores sociodemográficos (género e contexto habitacional), bem como uso/tipo de prótese e questões da ferramenta GOHA/ recorreu-se ao teste de Qui-Quadrado de 
Pearson. Caso se verificasse a violação da regra prática recorria-se ao teste Exato de Fisher (Maroco, 2003). Testou-se a hipótese nula ( $\mathrm{H}_{0}$ : não há associação entre as variáveis e contra a hipótese alternativa ( $\mathrm{H}_{1}$ : há associação entre as variáveis (Patrício at al, 2015).

Para comparar o aporte nutricional diário segundo o uso e tipo de prótese procedeu-se, inicialmente, à verificação da normalidade dos dados através do teste Kolmogorov-Smirnov com a correção de Lillefors $(N \geq 30)$ e à verificação da homogeneidade das variâncias com recurso ao teste de Levene. Quando verificadas estas duas condições, para duas amostras, recorreu-se ao teste $T$-Studente para K (mais de duas) amostras ao teste de ANOVA, ambos testes paramétricos. Quando uma destas condições foi violada, aplicou-se, para duas amostras, o teste de Mann-Whitney-Wilcoxon e para Kamostras o teste de Kruskal-Wallis, ambos testes não paramétricos (Maroco, 2003). Testou-se, assim, a hipótese nula ( $\mathrm{H}_{0}$ : não há diferenças, estatisticamente significativas, entre as amostras contra a hipótese alternativa $(\mathrm{H} T$ : há diferenças, estatisticamente significativas, entre as amostras (Patrício at al, 2015). Quando existiram diferenças, estatisticamente significativas, entre as amostras, recorreu-se à comparação múltipla de médias baseada no teste Post-Hoc - teste de Tukey, para identificar essas diferenças (Maroco, 2013).

O nível de significância usado foi de 5\% (grau de confiança de 95\%), considerando que este último valor se refere a um acontecimento que ocorre em apenas $5 \%$ das vezes, sendo considerado como muito raro. Portanto, é razoavelmente seguro rejeitar uma hipótese, quando os resultados das observações apenas têm uma probabilidade de ocorrência menor que $5 \%$, se essa hipótese for verdadeira (Oliveira, 2009).

\section{RESULTADOS}

Neste estudo foram incluídos 400 idosos, com idades compreendidas entre os 65 e 98 anos, sendo a média de $78( \pm 8,3)$ anos de idade. A tabela 1 revela que $71 \%$ dos indivíduos eram do género feminino e $29 \%$ do género masculino, sendo a maior percentagem de idosos jovens $(39,5 \%)$ e idosos velhos $(33,5 \%)$. Metade dos indivíduos eram residentes no distrito de Coimbra, $98 \%$ viviam no meio rural e mais de metade dos participantes eram casados $(51,5 \%)$. O nível de escolaridade predominante foi o 1 ociclo completo (40,3\%), 53\% dos participantes apresentavam um rendimento entre 0 IAS a1 IAS.

Tabela 1 - Estatística descritiva dos dados sociodemográficos dos idosos

\begin{tabular}{lllcc} 
& & $\mathbf{n}$ & $\mathbf{0}$ \\
\hline \multirow{2}{*}{ Género } & Feminino & 283 & 71,0 \\
\cline { 2 - 5 } & Masculino & 117 & 29,0 \\
\hline \multirow{3}{*}{ Idade } & Idosos jovens & 158 & 39,5 \\
\cline { 2 - 5 } & Idosos velhos & 134 & 33,5 \\
\cline { 2 - 5 } & Idosos mais velhos & 108 & 27,0 \\
\hline \multirow{3}{*}{ Distrito } & Coimbra & 200 & 50,0 \\
\cline { 2 - 5 } & Guarda & 108 & 27,0 \\
\cline { 2 - 5 } & Viseu & 92 & 23,0 \\
\hline \multirow{2}{*}{ Contexto Habitacional } & Rural & 393 & 98,2 \\
\cline { 2 - 5 } & Urbano & 7 & 1,8 \\
\hline \multirow{3}{*}{ Estado civil } & Solteiro & 29 & 7,3 \\
\cline { 2 - 5 } & Casado & 162 & 51,5 \\
\cline { 2 - 5 } & Viúvo & 40,5 \\
\hline
\end{tabular}




\begin{tabular}{|c|c|c|c|}
\hline & Separado / Divorciado & 3 & 0,8 \\
\hline \multirow{7}{*}{ Nível de Escolaridade } & Sem escolaridade & 91 & 22,8 \\
\hline & 1区 Ciclo Incompleto & 111 & 27,8 \\
\hline & 1区 Ciclo Completo & 161 & 40,3 \\
\hline & 2区 Ciclo Completo & 16 & 4,0 \\
\hline & 3区 Ciclo Completo & 8 & 2,0 \\
\hline & Ensino Secundário Completo & 6 & 1,5 \\
\hline & Ensino Superior Completo & 7 & 1,8 \\
\hline \multirow{5}{*}{ Rendimento } & $0|A S-1| A S$ & 212 & 53,0 \\
\hline & $1 I A S-2 I A S$ & 123 & 30,8 \\
\hline & 2 IAS - 3 IAS & 43 & 10,8 \\
\hline & 3 IAS - 4 IAS & 12 & 3,0 \\
\hline & Não soube responder & 10 & 2,5 \\
\hline
\end{tabular}

Relativamente à saúde oral, verificou-se que $66 \%$ dos participantes não iam anualmente ao dentista, sendo que a média de periodicidade de visitas a este profissional de saúde era de uma vez por ano e número máximo de consultas dentárias por ano era de seis. Da amostra, 57\% dos idosos eram portadores de prótese dentária, 2,6\% removiam-na no momento das refeições. A prótese dentária mais utilizada pelos participantes foi a prótese completa $(61 \%)$ (Tabela 2).

Tabela 2 - Estatística descritiva dos dados relativos à saúde oral dos idosos

\begin{tabular}{|c|c|c|c|c|}
\hline & & & \\
\hline & & & $\mathrm{n}$ & $\%$ \\
\hline \multirow{2}{*}{\multicolumn{2}{|c|}{ Visitas ao dentista }} & Sim & 136 & 34,0 \\
\hline & & Não & 264 & 66,0 \\
\hline \multirow{2}{*}{\multicolumn{2}{|c|}{ Prótese dentária }} & Sim & 228 & 57,0 \\
\hline & & Não & 172 & 43,0 \\
\hline \multirow{5}{*}{\multicolumn{2}{|c|}{ Tipo de prótese dentária }} & Prótese completa & 139 & 61,0 \\
\hline & & Prótese maxilar superior & 49 & 21,5 \\
\hline & & Prótese maxilar inferior & 9 & 3,9 \\
\hline & & Prótese parcial & 27 & 11,8 \\
\hline & & Implantes & 4 & 1,8 \\
\hline \multirow{2}{*}{\multicolumn{2}{|c|}{ Remoção da prótese dentária nas refeições }} & Sim & 6 & 2,6 \\
\hline & & Não & 222 & 97,4 \\
\hline \multirow{2}{*}{\multicolumn{2}{|c|}{$\begin{array}{l}\text { 1- Nos últimos } 3 \text { meses diminuiu a quantidade de alimentos } \\
\text { ou mudou o tipo de alimentação por causa dos seus dentes? }\end{array}$}} & Sim & 81 & 20,3 \\
\hline & & Não & 319 & 79,8 \\
\hline \multirow{19}{*}{ GOHAI } & \multirow{2}{*}{$\begin{array}{l}\text { 2- Nos últimos } 3 \text { meses teve problemas para mastigar } \\
\text { alimentos? }\end{array}$} & Sim & 156 & 39,0 \\
\hline & & Não & 344 & 61,0 \\
\hline & \multirow{2}{*}{$\begin{array}{l}\text { 3- Nos últimos } 3 \text { meses teve dor ou desconforto para engolir } \\
\text { alimentos? }\end{array}$} & Sim & 56 & 14,0 \\
\hline & & Não & 344 & 86,0 \\
\hline & \multirow{2}{*}{$\begin{array}{l}\text { 4- Nos últimos } 3 \text { meses mudou o seu modo de falar por } \\
\text { causa dos problemas da sua boca? }\end{array}$} & Sim & 63 & 15,8 \\
\hline & & Não & 337 & 84,3 \\
\hline & \multirow{2}{*}{$\begin{array}{l}\text { 5- Nos últimos } 3 \text { meses sentiu algum desconforto ao comer } \\
\text { algum alimento? }\end{array}$} & Sim & 79 & 19,8 \\
\hline & & Não & 321 & 80,3 \\
\hline & \multirow{2}{*}{$\begin{array}{l}\text { 6- Nos últimos } 3 \text { meses deixou de se encontrar com outras } \\
\text { pessoas por causa da sua boca? }\end{array}$} & Sim & 5 & 1,3 \\
\hline & & Não & 395 & 98,8 \\
\hline & \multirow{2}{*}{$\begin{array}{l}\text { 7- Nos últimos } 3 \text { meses sentiu-se satisfeito ou feliz com a } \\
\text { aparência da sua boca? }\end{array}$} & Sim & 255 & 63,8 \\
\hline & & Não & 145 & 36,3 \\
\hline & \multirow{2}{*}{$\begin{array}{l}\text { 8- Nos últimos } 3 \text { meses teve que tomar medicamentos para } \\
\text { passar a dor ou o desconforto da sua boca? }\end{array}$} & Sim & 17 & 4,3 \\
\hline & & Não & 383 & 95,8 \\
\hline & \multirow{2}{*}{$\begin{array}{l}\text { 9- Nos últimos } 3 \text { meses teve algum problema na sua boca } \\
\text { que o deixou preocupado? }\end{array}$} & Sim & 14 & 3,5 \\
\hline & & Não & 386 & 96,5 \\
\hline & \multirow{3}{*}{$\begin{array}{l}10-\text { Nos últimos } 3 \text { meses chegou a sentir-se nervoso por } \\
\text { causa dos problemas na sua boca? }\end{array}$} & Sim & 396 & 1,0 \\
\hline & & Não & 4 & 99,0 \\
\hline & & Sim & 0 & 0,0 \\
\hline
\end{tabular}




\begin{tabular}{llll}
\hline $\begin{array}{l}\text { 11- Nos últimos 3 meses evitou comer junto de outras } \\
\text { pessoas por causa de problemas na boca? }\end{array}$ & Não & 400 & 100,0 \\
\cline { 2 - 4 } $\begin{array}{l}\text { 12- Nos últimos 3 meses sentiu os seus dentes ou gengivas } \\
\text { ficarem sensíveis a alimentos ou líquidos? }\end{array}$ & Sim & 145 & 36,3 \\
\cline { 2 - 4 } & Não & 255 & 63,8 \\
\hline
\end{tabular}

Constata-se, também, através da tabela 2 que, nos últimos três meses, 20,3\% dos idosos diminuíram a quantidade de alimentos ou mudaram o tipo de alimentação por causa dos dentes, 39\% tiveram problemas em mastigar os alimentos, $14 \%$ tiveram dor ou desconforto em engolir alimentos, 15,8\% mudaram o modo de falar devido aos problemas na cavidade oral, $19,7 \%$ sentiram algum desconforto ao ingerirem algum alimento, 1,3\% deixaram de se encontrar com outras pessoas por causa da aparência da cavidade oral, 63,7\% sentiam-se satisfeitos ou felizes com a aparência da mesma. E ainda que 4,3\% tomavam medicamentos para alivar a dor ou desconforto proveniente da cavidade oral, 3,5\% tiveram algum problema na cavidade oral que os deixaram preocupados, $1 \%$ chegaram a sentirem-se nervosos devido aos problemas na sua cavidade oral, $36,3 \%$ sentiram os seus dentes ou gengivas ficarem sensíveis a alimentos ou líquidos e $100 \%$ dos idosos não evitaram comer junto de outras pessoas devido aos problemas na cavidade oral.

Relativamente aos fatores sociodemográficos, apenas se verificou correlação $(p=0,006)$, estatisticamente significativa, entre o nível de escolaridade e periodicidade de idas ao dentista, sendo esta correlação positiva fraca $(r=0,231)$, atendendo que à medida que aumenta a literacia dos idosos, aumenta o número de visitas ao dentista. Constatou-se associação, estatisticamente significativa, entre o género e uso de prótese dentária $(p=0,000)$, sendo o uso de prótese superior no género feminino. Existe também associação, estatisticamente significativa, entre o uso de prótese e nível de escolaridade $(p=0,007)$, uma vez que a prótese dentária é mais utilizada por indivíduos com maior nível de escolaridade, mas também pelos idosos que tinham o 1o ciclo incompleto e completo. Verificou-se ainda associação, estatisticamente significativa, entre o tipo de prótese dentária e rendimento $(p=0,08)$, sendo que os indivíduos portadores de prótese completa, prótese no maxilar inferior ou implantes, tinham menor rendimento relativamente aos idosos com prótese no maxilar superior ou com prótese parcial (Tabela 3). 
Tabela 3 - Caraterização dos fatores sociodemográficos segundo a periodicidade de visitas ao dentista, uso e tipo de prótese dentária

\begin{tabular}{|c|c|c|c|c|c|c|c|c|c|c|c|c|c|c|c|c|c|c|c|c|c|c|c|c|c|}
\hline & & \multirow{3}{*}{$\begin{array}{l}\text { spade } \\
\text { spearman }\end{array}$} & \multirow{3}{*}{$\underset{\substack{p-\\
\text { valuo }}}{ }$} & \multicolumn{6}{|c|}{ Periodididade de idas a a dentista } & \multirow{3}{*}{$p$-value } & \multicolumn{4}{|c|}{ Uso de protese dentaria } & \multirow{3}{*}{$p$-value } & \multicolumn{10}{|c|}{ Tipo de proleses dent aria } \\
\hline & & & & \multicolumn{2}{|c|}{1} & \multicolumn{2}{|c|}{2} & \multicolumn{2}{|c|}{3 ou mais } & & \multicolumn{2}{|c|}{ Nào } & \multicolumn{2}{|c|}{ sim } & & \multicolumn{2}{|c|}{$\begin{array}{l}\text { Protese } \\
\text { Completa }\end{array}$} & \multicolumn{2}{|c|}{$\begin{array}{l}\text { Probose } \\
\text { Naxilar } \\
\text { Superior } \\
\end{array}$} & \multicolumn{2}{|c|}{$\begin{array}{c}\text { Protese Maxilar } \\
\text { Inferior }\end{array}$} & \multicolumn{2}{|c|}{ Implantes } & \multicolumn{2}{|c|}{ Frotese Parcial } \\
\hline & & & & $n$ & $\%$ & $n$ & $\%$ & $n$ & $\%$ & & $n$ & $\%$ & $\mathrm{n}$ & $\%$ & & $n$ & $\%$ & $n$ & $\%$ & $n$ & $\%$ & $n$ & $\%$ & $n$ & $\%$ \\
\hline \multirow{2}{*}{ Genero } & Feninino & \multirow[b]{2}{*}{ - } & \multirow{2}{*}{0.129} & 53 & 58,2 & 25 & 27.5 & 13 & 14.3 & \multirow{2}{*}{0,0000} & 103 & 36,4 & 180 & 63,6 & \multirow{2}{*}{$0.056 c^{6}$} & 112 & 62,2 & 40 & 22,2 & 9 & 5,0 & 3 & 1.7 & 16 & 8.9 \\
\hline & Masculino & & & 26 & 56.5 & 18 & 39.1 & 2 & 4.3 & & 69 & 59.0 & 48 & 41,0 & & 27 & 56,3 & 9 & 18.8 & 0 & 0.0 & 1 & 2,1 & 11 & 22,9 \\
\hline & Idososs jovens & & & 42 & 53.2 & 29 & 36,7 & 8 & 10,1 & & 62 & 39,2 & 96 & 60,8 & & 49 & 51,0 & 27 & 28,1 & 4 & 4,2 & 2 & 2,1 & 14 & 14,6 \\
\hline Idade & Idosososvelhos & $-0,17$ & 0,175 & 25 & 58,1 & 11 & 25,6 & 7 & 16,3 & 0.458 & 60 & 44,8 & 74 & 55.2 & $0,585 \varepsilon^{-}$ & 50 & 67,6 & 14 & 18,9 & 1 & 1,4 & 1 & 1,4 & 8 & 10,8 \\
\hline & Idososmais velhos & & & 12 & 80,0 & 3 & 20,0 & 0 & 0,0 & & 50 & 46,8 & 59 & 53,7 & & 40 & 69,0 & 8 & 13,8 & 4 & 6.9 & 1 & 1.7 & 5 & 8,6 \\
\hline Contexto & Untano & & 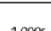 & 2 & 66,7 & 1 & 33,3 & 0 & 0.0 & 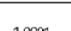 & 3 & 42,9 & 4 & 57,1 & o & 2 & 50,0 & 2 & 50.0 & 0 & 0.0 & 0 & 0.0 & 0 & 0.0 \\
\hline Habitiacional & Rural & & $1,000^{6}$ & $\pi$ & 57,5 & 42 & 31,3 & 15 & 11,2 & $1,000^{\circ}$ & 169 & 43,0 & 224 & 57.0 & $0,4456^{6}$ & 137 & 61,2 & 47 & 21,0 & 9 & 4.0 & 4 & 1.8 & 27 & 12,1 \\
\hline & Semesolanidade & & & 10 & 83,3 & 1 & 8,3 & 1 & 8.3 & & 53 & 58.2 & 39 & 411.8 & & 28 & 73,7 & 7 & 18,4 & 2 & 5.3 & 0 & 0.0 & 1 & 2.6 \\
\hline & 1) Cicto Incompleto & & & 19 & 59.4 & 12 & 37.5 & 1 & 3,1 & & 41 & 369 & 70 & 63.1 & & 49 & 70,0 & 8 & 11.4 & 2 & 2,9 & 2 & 2,9 & 9 & 12,9 \\
\hline & 1: CidaCompleto & & & 42 & 60.0 & 21 & 30,0 & 7 & 10.0 & & 61 & 37,9 & 100 & 62,1 & & 53 & 53,0 & 26 & 26,0 & 5 & 5,0 & 2 & 222,0 & 14 & 14,0 \\
\hline $\begin{array}{c}\text { Nwelded } \\
\text { escolaridade }\end{array}$ & 2:Cicla Completo & 0,231 & $0.000^{\circ}$ & 4 & 50,0 & 2 & 25,0 & 2 & 25,0 & $0.0070 \%$ & 7 & 43,8 & 9 & 56,3 & $0.139 \mathrm{c}$ & 2 & 22,2 & 6 & 66.7 & 0 & 0,0 & 0 & 0.0 & 1 & 11,1 \\
\hline & 3 Cicla Completo & & & 2 & 28,6 & 4 & 57,1 & 1 & 14,3 & & 5 & 62,5 & 3 & 37.5 & & 1 & 33,3 & 1 & 33,3 & 0 & 0.0 & 0 & 0.0 & 1 & 33,3 \\
\hline & Ensino Secundario Completto & & & 1 & 20,0 & 1 & 20,0 & 3 & 60,0 & & 4 & 66,7 & 2 & 33,3 & & 0 & 0.0 & 1 & 50,0 & 0 & 0,0 & 0 & 0,0 & 1 & 50,0 \\
\hline & Ensino Superior Completo & & & 1 & 33.3 & 2 & 66,7 & 0 & 0.0 & & 1 & 14,3 & 6 & 85.7 & & 6 & 100 & 0 & 0.0 & 0 & 0.0 & 0 & 0.0 & 0 & 0.0 \\
\hline & OIAS-11AS & & & 27 & 58,7 & 16 & 34,8 & 3 & 6,5 & & 104 & 49,1 & 108 & 50.9 & & 74 & 68.5 & 16 & 14.8 & 6 & 5.6 & 2 & 1.9 & 10 & 9.3 \\
\hline & 1IAS-2IAS & & & 33 & 61,1 & 14 & 25,9 & 7 & 13,0 & & 45 & 36,6 & 78 & 63,4 & & 46 & 59,0 & 21 & 26,9 & 1 & 1.3 & 2 & 2,6 & 3 & 10.3 \\
\hline Rendimento & 2IAS-3IAS & 0.074 & 0,389 & 14 & $\begin{aligned} 53.8 \\
\end{aligned}$ & 10 & 38.5 & 2 & 7.7 & 0.114 & 16 & 37,2 & 27 & 62,8 & $0,00 g^{20 x}$ & 15 & 55,6 & 7 & 25,9 & 2 & 7,4 & 0 & 0,0 & 3 & 11,1 \\
\hline & 3IAS-41AS & & & 3 & 33.3 & 3 & 33,3 & 3 & 33,3 & & 3 & 25,0 & 9 & 75,0 & & 0 & 0.0 & 3 & 33,3 & 0 & 0.0 & 0 & 0.0 & 6 & 66,7 \\
\hline & Naa soube responder & & & 2 & 100,0 & 0 & 0,0 & 0 & 0,0 & & 4 & 40 & 6 & 60,0 & & 4 & 66.7 & 2 & 33,3 & 0 & 0.0 & 0 & 0.0 & 0 & 0,0 \\
\hline Usode & Nào & 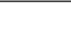 & 0 & 29 & 54,7 & 20 & 37,7 & 4 & 7.5 & & & & & & & & & & & & & & & & \\
\hline protiesese & $\mathrm{sim}$ & - & 0,341 & 50 & 59,5 & 23 & 27,4 & 11 & 13,1 & & & & & & & & & & & $c$ & , & $\operatorname{sign}$ & cânc & de $5 \%$ & \\
\hline & Protesese Completa & & & 19 & 61.3 & 2 & 25,8 & 4 & 12,9 & & & & & & 2 & cativa & entre & & riáve & aor & vet & , & ância & $5 \%$ & \\
\hline & Prothese Maxilat Siperix & & & 18 & 64,3 & 5 & 7.9 & 5 & 17.9 & & & & ats & So & este & ato & Mont & 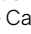 & & & & & & & \\
\hline $\begin{array}{l}\text { Tipode } \\
\text { protites }\end{array}$ & Protese Maxilar Inferior & - & 0,429 & 3 & 50,0 & 2 & 33,3 & 1 & 16,7 & & & obtic & atra & rés do & Teste E & ato d & Fishe & & & & & & & & \\
\hline & Implantes & & & 3 & 100,0 & 0 & 0.0 & 0 & 0.0 & & & & & & & & & & & & & & & & \\
\hline & Protese Parcial & & & 7 & 43,8 & 8 & 50,0 & 1 & 6.3 & & & & & & & & & & & & & & & & \\
\hline
\end{tabular}


Como se pode constatar na tabela 4, verificou-se associação, estatisticamente significativa, entre o uso de prótese dentária e questão 1, 2, 3, 5, 7 e 12 do GOHAl (questões relativas à dimensão física: padrão de mastigação, fala e deglutição; dimensão psicossocial: satisfação com a aparência da boca) $(p<0,05)$. Os dados constantes na mesma tabela mostram ainda que, não houve nenhuma associação, estatisticamente significativa, entre o tipo de prótese dentária e as 12 questões da ferramenta GOHAI ( $p>0,05)$. Não foi possível aplicar nenhum teste estatístico na questão 11, uma vez que todos os participantes mencionaram a mesma resposta.

Tabela 4 - Caraterização das questões da ferramenta GOHAI, segundo o uso e tipo de prótese dentária

\begin{tabular}{|c|c|c|c|c|c|c|c|c|c|c|c|c|c|c|c|c|c|c|}
\hline & & & \multicolumn{5}{|c|}{ Uso de prótese dentária } & \multicolumn{11}{|c|}{ Tipos de prótese dentária } \\
\hline & & & \multirow[t]{2}{*}{$p$-value } & \multicolumn{2}{|c|}{ Não } & \multicolumn{2}{|c|}{ Sim } & \multirow[t]{2}{*}{$p$-value } & \multicolumn{2}{|c|}{$\begin{array}{c}\text { Prótese } \\
\text { Completa }\end{array}$} & \multicolumn{2}{|c|}{$\begin{array}{c}\text { Prótese } \\
\text { Maxilar } \\
\text { Superior } \\
\end{array}$} & \multicolumn{2}{|c|}{$\begin{array}{l}\text { Prótese } \\
\text { Maxilar } \\
\text { Inferior }\end{array}$} & \multicolumn{2}{|c|}{ Implantes } & \multicolumn{2}{|c|}{$\begin{array}{l}\text { Prótese } \\
\text { Parcial }\end{array}$} \\
\hline & & & & $n$ & $\%$ & $n$ & $\%$ & & $n$ & $\%$ & $n$ & $\%$ & $n$ & $\%$ & $n$ & $\%$ & $n$ & $\%$ \\
\hline \multirow{24}{*}{$\begin{array}{l}\text { ᄋ } \\
\stackrel{0}{1} \\
\text { ㄹ }\end{array}$} & \multirow{2}{*}{1} & Não & \multirow{2}{*}{$0,001^{a}$} & 124 & 38,9 & 195 & 61,1 & \multirow{2}{*}{$0,674^{c}$} & 118 & 60,5 & 41 & 21,0 & 7 & 3,6 & 4 & 2,1 & 25 & 12,8 \\
\hline & & Sim & & 48 & 59,3 & 33 & 40,7 & & 21 & 63,6 & 8 & 24,2 & 2 & 6,1 & 0 & 0,0 & 2 & 6,1 \\
\hline & \multirow{2}{*}{2} & Não & \multirow{2}{*}{$0,000^{\mathrm{a}}$} & 86 & 35,2 & 158 & 64,8 & \multirow{2}{*}{$0,151^{\circ}$} & 96 & 60,8 & 32 & 20,3 & 4 & 2,5 & 4 & 2,5 & 22 & 13,9 \\
\hline & & Sim & & 86 & 55,1 & 70 & 44,9 & & 43 & 61,4 & 17 & 24,3 & 5 & 7,5 & 0 & 0,0 & 5 & 7,1 \\
\hline & \multirow{2}{*}{3} & Não & \multirow{2}{*}{$0,044^{\mathrm{a}}$} & 141 & 41,0 & 203 & 59,0 & \multirow{2}{*}{$0,176^{c}$} & 122 & 60,1 & 43 & 21,2 & 8 & 3,9 & 4 & 2,0 & 26 & 12,8 \\
\hline & & Sim & & 31 & 55,4 & 25 & 44,6 & & 17 & 68,0 & 6 & 24,0 & 1 & 4,0 & 0 & 0,0 & 1 & 4,0 \\
\hline & \multirow{2}{*}{4} & Nào & \multirow{2}{*}{0,596} & 143 & 42,5 & 195 & 57,6 & \multirow{2}{*}{$0,149^{c}$} & 115 & 59,3 & 43 & 22,2 & 6 & 3,1 & 4 & 2,1 & 26 & 13,4 \\
\hline & & Sim & & 29 & 46,0 & 34 & 54,0 & & 24 & 70,6 & 6 & 17,6 & 3 & 8,8 & 0 & 0,0 & 1 & 2,9 \\
\hline & \multirow{2}{*}{5} & Não & \multirow{2}{*}{$0,022^{\mathrm{a}}$} & 129 & 40,2 & 192 & 59,8 & ore & 115 & 59,9 & 40 & 20,8 & 8 & 4,2 & 4 & 2,1 & 25 & 13,0 \\
\hline & & Sim & & 43 & 54,4 & 36 & 45,6 & 0,014 & 24 & 66,7 & 9 & 25,0 & 1 & 2,8 & 0 & 0,0 & 2 & 5,6 \\
\hline & , & Não & (1) & 170 & 43,0 & 225 & 57,0 & & 138 & 61,3 & 47 & 20,9 & 9 & 4,0 & 4 & 1,8 & 27 & 12,0 \\
\hline & ${ }^{\circ}$ & Sim & 1,000 & 2 & 40,0 & 3 & 60,0 & 0,317 & 1 & 33,3 & 2 & 66,7 & 0 & 0,0 & 0 & 0,0 & 0 & 0,0 \\
\hline & & Não & 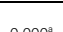 & 97 & 66,9 & 48 & 33,1 & 0. & 26 & 54,2 & 15 & 31,3 & 2 & 4,2 & 1 & 2,1 & 4 & 8,3 \\
\hline & I & Sim & $0,000^{\circ}$ & 75 & 29,4 & 180 & 70,6 & $0,429^{2}$ & 113 & 62,8 & 34 & 18,9 & 7 & 3,9 & 3 & 1,7 & 23 & 12,8 \\
\hline & 8 & Não & 0097 & 168 & 43,9 & 215 & 56,1 & $0806^{c}$ & 131 & 60,9 & 45 & 20,9 & 9 & 4,2 & 4 & 1,9 & 26 & 12,1 \\
\hline & 0 & Sim & 0,007 & 23,5 & 4,0 & 13 & 76,5 & & 8 & 61,5 & 4 & 30,8 & 0 & 0,0 & 0 & 0,0 & 1 & 7,7 \\
\hline & o & Não & ( & 166 & 43,0 & 220 & 57,0 & SOP & 136 & 61,8 & 44 & 20,0 & 9 & 4,1 & 4 & 1,8 & 27 & 12,3 \\
\hline & ( & $\mathrm{Sim}$ & (19) & 6 & 42,9 & 8 & 57,1 & 0,094 & 3 & 37,5 & 5 & 62,4 & 0 & 0,0 & 0 & 0,0 & 0 & 0,0 \\
\hline & 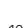 & Nào & ( & 170 & 42,9 & 226 & 57,1 & 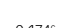 & 139 & 61,5 & 47 & 20,8 & 9 & 4,0 & 4 & 1,8 & 27 & 11,9 \\
\hline & 10 & Sim & 1,000 & 2 & 50,0 & 2 & 50,0 & $0,1 / 4$ & 0 & 0,0 & 2 & 100,0 & 0 & 0,0 & 0 & 0,0 & 0 & 0,0 \\
\hline & & Não & & 172 & 43,0 & 43 & 228,0 & & 139 & 61,0 & 49 & 21,5 & 9 & 3,9 & 4 & 1,8 & 27 & 11,8 \\
\hline & & Sim & & 0 & 0,0 & 0 & 0,0 & & 0 & 0,0 & 0 & 0,0 & 0 & 0,0 & 0 & 0,0 & 0 & 0,0 \\
\hline & 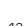 & Não & r & 96 & 37,6 & 159 & 62,4 & 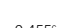 & 95 & 59,7 & 32 & 20,1 & 6 & 3,8 & 3 & 1,9 & 23 & 14,5 \\
\hline & 12 & Sim & 0,004 & 76 & 52,4 & 69 & 47,6 & 0,450 & 44 & 63,8 & 17 & 24,6 & 3 & 4,3 & 1 & 1,4 & 4 & 5,8 \\
\hline
\end{tabular}

a Há associação, estatisticamente significativa, entre as variáveis, ao nível de significância de 5\%

${ }^{\mathrm{b}}$ Resultado obtido através do Teste Exato de Fisher

${ }^{\mathrm{c} R e s u l t a d o}$ obtido através do Teste Exato de Monte Carlo

Averiguou-se, também, que não existe nenhuma associação, estatisticamente significativa, entre o modo de confeção das refeições principais e o uso, tipo de prótese dentária $(p>0,05)$, isto é, o uso deste tratamento de reabilitação não condiciona o modo de confeção da refeição do almoço e jantar (Tabela 5). 
Tabela 5 - Caraterização do modo de confeção das refeições principais, segundo o uso e tipo de prótese dentária

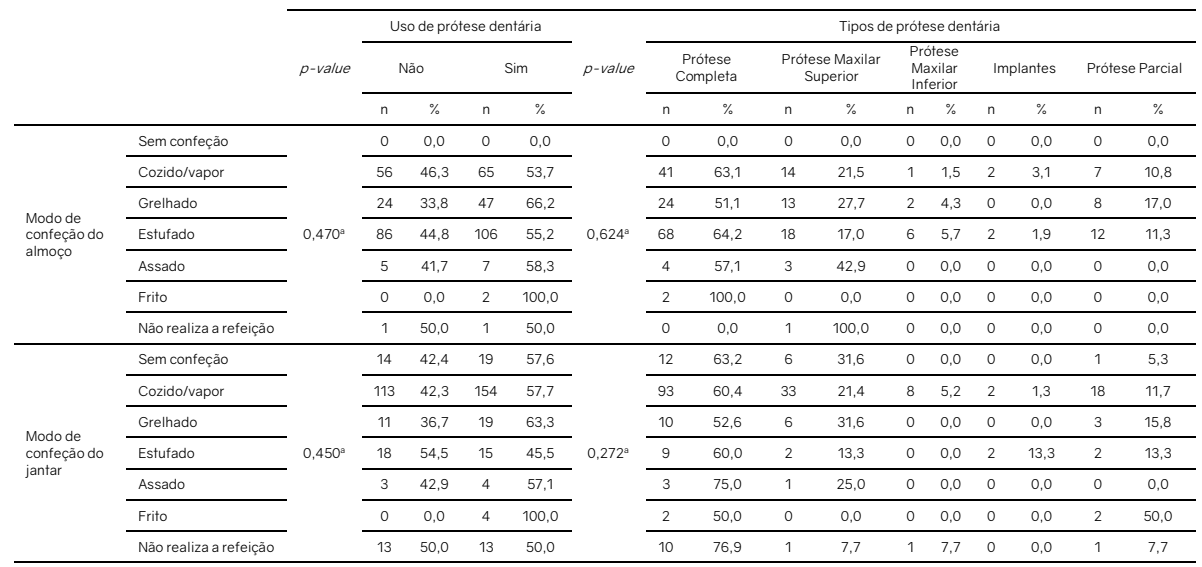

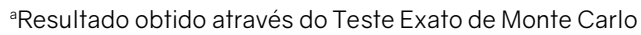

Relativamente ao aporte nutricional diário dos idosos, tendo em conta o uso de prótese dentária, verificaram-se diferenças, estatisticamente significativas, entre o aporte diário de ferro $(p=0,014)$ e fósforo $(p=0,042)$, sendo que esse aporte era superior nos participantes não portadores de prótese, como se constata na tabela 6 . Ainda nesta tabela, verifica-se, quando comparado o aporte nutricional diário dos idosos, considerando o tipo de prótese usado, diferenças, estatisticamente significativas, no que diz respeito ao aporte diário de proteína total, proteína de baixo valor biológico, vitamina $A$, carotenos, $\alpha$ - tocoferol, cinza, magnésio $(p<0,05)$, verificando-se que os idosos com implantes apresentavam aporte superior destes nutrientes.

Tabela 6: Caraterização do aporte nutricional diário, segundo o uso e tipo de prótese dentária

\begin{tabular}{|c|c|c|c|c|c|c|c|c|c|}
\hline & \multirow[b]{2}{*}{$p$-value } & \multicolumn{2}{|c|}{ Uso de prótese dentária } & \multirow[b]{2}{*}{$p$-value } & \multicolumn{5}{|c|}{ Tipo de prótese dentária } \\
\hline & & $\operatorname{Sim}$ & Não & & $\begin{array}{l}\text { Prótese } \\
\text { completa }\end{array}$ & $\begin{array}{c}\text { Prótese } \\
\text { maxilar } \\
\text { superior }\end{array}$ & $\begin{array}{l}\text { Prótese } \\
\text { maxilar } \\
\text { inferior }\end{array}$ & $\begin{array}{c}\text { Prótese } \\
\text { parcial }\end{array}$ & Implantes \\
\hline Energia/dia (kcal) & $0,286^{a}$ & 1696,8 & 1714,7 & $0,152^{c}$ & 1651,6 & 1734,7 & 1712,4 & 1883,6 & 2433,0 \\
\hline Água/dia (ml) & $0,125^{a}$ & 2050,6 & 2112,0 & $0,127^{c}$ & 2075,5 & 1907,4 & 1897,5 & 2167,5 & 3193,8 \\
\hline Proteina Total/dia (g) & $0,105^{a}$ & 62,1 & 67,8 & $0,046^{c, e}$ & 60,4 & 66,1 & 61,5 & 66,0 & 90,8 \\
\hline Proteina AVB/dia (g) & $0,098^{\mathrm{a}}$ & 34,4 & 38,1 & $0,239^{c}$ & 32,7 & 35,7 & 31,3 & 35,9 & 48,1 \\
\hline Proteina BVB/dia (g) & $0,430^{a}$ & 26,0 & 26,8 & $0,044^{\text {cee }}$ & 25,0 & 26,6 & 29,6 & 25,0 & 35,8 \\
\hline Gordura total/dia (g) & $0,378^{\mathrm{a}}$ & 46,1 & 50,1 & $0,198^{\circ}$ & 45,3 & 45,5 & 44,2 & 49,2 & 72,6 \\
\hline HC total/dia (g) & $0,582^{\mathrm{a}}$ & 229,0 & 238,4 & $0,180^{\circ}$ & 220,8 & 231,0 & 253,4 & 256,4 & 343,7 \\
\hline Mono e dissacarideos/dia (g) & $0,436^{a}$ & 73,2 & 79,2 & $0,124^{c}$ & 70,2 & 72,5 & 65,1 & 87,7 & 108,9 \\
\hline Álcool/dia (g) & $0,056^{\mathrm{a}}$ & 0,0 & 0,0 & $0,367^{\circ}$ & 0,0 & 0,0 & 0,0 & 0,0 & 3,5 \\
\hline Amido/dia (g) & $0,781^{\mathrm{a}}$ & 154,9 & 153,1 & $0,083^{c}$ & 153,7 & 155,6 & 185,3 & 151,1 & 231,1 \\
\hline Fibra alimentar/dia (g) & $0,342^{\mathrm{b}}$ & 20,9 & 21,6 & $0,018^{c}$ & 18,9 & 21,2 & 22,3 & 23,1 & 31,2 \\
\hline Saturados/dia (g) & $0,550^{\mathrm{a}}$ & 13,9 & 14,6 & $0,262^{c}$ & 13,6 & 14,6 & 12,7 & 14,5 & 19,9 \\
\hline Monoinsaturados/dia (g) & $0,623^{a}$ & 18,3 & 18,9 & $0,178^{c}$ & 17,8 & 18,2 & 18,5 & 22,5 & 29,6 \\
\hline Polinsaturados/dia (g) & $0,109^{\mathrm{a}}$ & 7,7 & 8,4 & $0,182^{c}$ & 7,1 & 8,0 & 8,1 & 8,5 & 13,3 \\
\hline Trans/dia (g) & $0,995^{a}$ & 0,7 & 0,7 & $0,543^{c}$ & 0,7 & 0,8 & 0,8 & 0,8 & 0,9 \\
\hline Ácido linoleico/dia (g) & $0,162^{\mathrm{a}}$ & 5,5 & 6,3 & $0,188^{c}$ & 5,4 & 5,6 & 7,0 & 6,6 & 10,7 \\
\hline Colesterol/dia (mg) & $0,232^{\mathrm{a}}$ & 115,6 & 129,9 & $0,233^{c}$ & 112,1 & 134,5 & 105,7 & 127,5 & 145,6 \\
\hline
\end{tabular}




\begin{tabular}{|c|c|c|c|c|c|c|c|c|c|}
\hline Vitamina A/dia ( $\mu \mathrm{g}$ ) & $0,347^{\mathrm{a}}$ & 574,0 & 613,6 & $0,001^{c, e}$ & 507,9 & 580,4 & 710,8 & 679,5 & 1020,3 \\
\hline Caroteno/dia ( $\mu \mathrm{g})$ & $0,416^{\mathrm{a}}$ & 2535,2 & 2736,7 & $0,001^{c, e}$ & 2109,9 & 2414,8 & 3296,6 & 3285,4 & 5131,7 \\
\hline Vitamina D/dia ( $\mu \mathrm{g})$ & $0,629^{3}$ & 7,6 & 7,8 & $0,130^{c}$ & 7,5 & 8,8 & 7,6 & 7,4 & 16,3 \\
\hline$\alpha$ Tocoferol/dia (mg) & $0,773^{\mathrm{a}}$ & 7,5 & 7,6 & $0,045^{c, e}$ & 6,9 & 7,8 & 7,4 & 9,7 & 12,1 \\
\hline Tiamina/dia (mg) & $0,503^{a}$ & 1,2 & 1,2 & $0,193^{c}$ & 1,2 & 1,3 & 1,3 & 1,1 & 1,8 \\
\hline Riboflavina/dia (mg) & $0,059^{a}$ & 1,4 & 1,4 & $0,232^{d}$ & 1,3 & 1,4 & 1,3 & 1,5 & 1,5 \\
\hline Niacina/dia (mg) & $0,247^{a}$ & 29,6 & 31,5 & $0,096^{c}$ & 29,4 & 29,8 & 27,2 & 30,1 & 42,7 \\
\hline Triptofano/dia (mg) & $0,463^{a}$ & 17,3 & 17,9 & $0,135^{\circ}$ & 17,1 & 18,1 & 15,7 & 16,7 & 24,9 \\
\hline Vitamina B6/dia (mg) & $0,118^{a}$ & 12,7 & 13,9 & $0,051^{c}$ & 12,2 & 13,7 & 12,6 & 12,7 & 18,1 \\
\hline Vitamina B12/dia (mg) & $0,938^{\mathrm{a}}$ & 1,9 & 1,8 & $0,224^{c}$ & 1,9 & 1,9 & 2,1 & 1,8 & 3,1 \\
\hline Vtamina C/dia (mg) & $0,438^{9}$ & 3,4 & 3,6 & $0,205^{c}$ & 3,4 & 3,4 & 3,1 & 3,2 & 6,4 \\
\hline Folatos/dia ( $\mu \mathrm{g}$ ) & $0,159^{a}$ & 101,4 & 96,3 & $0,131^{c}$ & 97,4 & 108,0 & 87,1 & 118,0 & 143,0 \\
\hline Cinza/dia (mg) & $0,854^{a}$ & 198,8 & 195,1 & $0,036^{c, e}$ & 181,3 & 204,1 & 201,6 & 207,8 & 284,5 \\
\hline Equivalentes niacina/dia(g) & $0,143^{\mathrm{a}}$ & 14,3 & 14,8 & $0,053^{d}$ & 13,8 & 14,7 & 14,2 & 15,0 & 18,3 \\
\hline $\mathrm{Na} / \mathrm{dia}$ (mg) & $0,065^{a}$ & 1998,4 & 2224,6 & $0,236^{c}$ & 1915,5 & 2098,9 & 2989,1 & 2061,6 & 2653,9 \\
\hline $\mathrm{K} / \mathrm{dia}$ (mg) & $0,440^{3}$ & 3215,2 & 3325,3 & $0,499^{\circ}$ & 3157,5 & 3269,6 & 3437,2 & 3243,2 & 4579,3 \\
\hline $\mathrm{Fe} /$ dia (mg) & $0,014^{e}$ & 7,9 & 8,8 & $0,130^{c}$ & 7,6 & 8,3 & 7,9 & 8,6 & 11,3 \\
\hline $\mathrm{Zn/dia} \mathrm{(mg)}$ & $0,091^{a}$ & 8,0 & 8,3 & $0,082^{c}$ & 7,7 & 8,0 & 8,2 & 8,7 & 11,6 \\
\hline $\mathrm{Ca} / \mathrm{dia}$ (mg) & $0,080^{b}$ & 624,7 & 673,8 & $0,154^{d}$ & 549,0 & 660,0 & 643,9 & 709,6 & 769,0 \\
\hline $\mathrm{P} / \mathrm{dia}$ (mg) & $0,042^{\mathrm{b}, \mathrm{e}}$ & 1039,2 & 1110,4 & $0,127^{d}$ & 1002,2 & 1070,3 & 1080,8 & 1078,4 & 1374,3 \\
\hline Mg/dia (mg) & $0,121^{\mathrm{b}}$ & 231,7 & 242,1 & $0,048^{d, e}$ & 223,1 & 237,2 & 229,6 & 243,3 & 305,8 \\
\hline
\end{tabular}

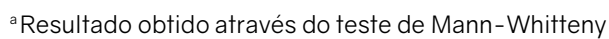

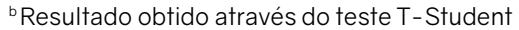

'Resultado obtido através do teste de Kruskal-Wallis

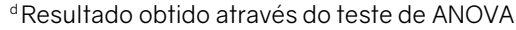

\section{DISCUSSÃO}

Portugal é dos países europeus com taxas de tratamento dentário mais baixas, estimando-se que, aproximadamente, $50 \%$ da população portuguesa não recorre a cuidados de saúde oral por motivos financeiros, resultando a procura de tratamentos dentários apenas em situações de urgência (Sousa, 2016). Neste estudo verificou-se também um baixo recurso aos serviços odontológicos por parte da população geriátrica, uma vez que apenas $34 \%$ da população costuma ir ao dentista, entre 1 a 6 vezes por ano. Muito embora a saúde oral em Portugal esteja inserida em programas de cuidados de saúde primários, a maioria desses serviços de medicina dentária continuam a ser prestados pelo sector privado, o que constitui uma barreira na acessibilidade aos cuidados de saúde oral (Sousa, 2016). Matos e Lima-Costa (2007) averiguaram que o género, faixa etária, escolaridade, rendimento e situação domiciliar apresentaram associações estatisticamente significativas $(p<0,001)$ com o tempo decorrido após a última visita ao dentista. Constataram ainda que o género masculino apresentou menor probabilidade de visitar o dentista há mais de um ano comparativamente com o género feminino; que com o aumento da idade existiu uma menor frequência de visitas ao dentista; que os idosos residentes na zona rural apresentaram menor frequência de visitas a este profissional de saúde, assim como maior prevalência daqueles que relataram nunca terem ido a uma consulta. Também verificaram que uma maior escolaridade e renda domiciliar eram fatores preditores de maior frequência aos serviços odontológicos (Matos et al, 2007). Estes resultados são semelhantes aos de Ferreira et al. (2013) que verificaram que os idosos com maior rendimento e nível de escolaridade apresentavam maior prevalências de utilização recente dos serviços odontológicos $(p<0,001)$. No presente estudo, verificou-se correlação, estatisticamente significativa, entre a periodicidade de visitas ao dentista e o nível de escolaridade, atendendo que à medida que aumenta a literacia dos idosos, aumenta o número de idas ao dentista $(p=0,006)$, uma vez que o aumento da informação possibilita o aumento do 
conhecimento relativo à importância do uso regular dos serviços odontológicos, resultados esses que coincidem com os encontrados nos estudos mencionados.

Relativamente ao tratamento dentário, estudo de Cardoso et al. (2011) verificaram, com significância estatística, que o uso de prótese completa ou parcial é superior no género feminino, em comparação com o género masculino $(p<0,001)$. Como se pode constatar no presente estudo (tabela 3), ainda que o uso de prótese completa ou parcial seja superior no género feminino, não se verificou nenhuma associação, estatisticamente significativa $(p>0,05)$.

Verificou-se que, nos últimos 3 meses, quem não diminuiu a quantidade de alimentos ou mudou o tipo de alimentação por causa dos seus dentes, quem não teve problemas para mastigar os alimentos; quem não teve dor ou desconforto em engolir alimentos; quem não sentiu algum desconforto ao comer alimentos e quem não sentiu os seus dentes ou gengivas ficarem sensíveis a alimentos ou líquidos, foi a maioria dos indivíduos que usavam prótese dentária. E os indivíduos que se sentiam mais satisfeitos ou felizes com a aparência da sua boca foram os indivíduos portadores de prótese dentária. Estes resultados concorrem para o princípio de que a prótese dentária confere um maior conforto e um bom estado dentário aos seus portadores, ao reestabelecer a capacidade mastigatória, a estética e a fonação e, consequentemente, melhor qualidade de vida, eliminando possíveis desconfortos na hora da refeição e momentos de socialização (Lopes et al., 2014).

$\mathrm{Na}$ análise do aporte nutricional diário dos idosos, verificou-se que os indivíduos portadores de prótese completa têm menor aporte diário de proteína total, ferro, niacina, riboflavina, vitamina B6 e folatos, comparativamente com idosos portadores de prótese parcial, mas têm aporte superior em vitamina 12 e tiamina. Tais dados são controversos com os de Goel et al. (2016), que referem como conclusão do seu estudo, que os indivíduos com prótese completa apresentavam maiores valores de proteína, ferro e vitamina B em comparação com os grupos IRPD e FPD e que apresentam maior aporte de hidratos de carbono e energia relativamente ao grupo FPD. Estes resultados não se verificaram no presente estudo, uma vez que não se avaliou o estado da prótese do idoso, ou seja, se a prótese completa estava ou não bem-adaptada ao estado dentário do individuo. Este fator pode ser determinante para uma melhor ou pior ingestão alimentar relativamente ao grupo da carne e peixe, o que altera o aporte nutricional dos idosos relativamente à proteína total, ferro e vitamina $\mathrm{B}$.

Estudo realizado por Han e Kim (2014), verificaram que os participantes portadores de prótese dentária apresentavam aportes mais elevados, com significância estatística, de fósforo, ferro, potássio, niacina e vitamina $\mathrm{C}$. No presente estudo isto não se verificou, sendo que os não portadores de prótese dentária tinham um maior aporte diário dos micronutrientes anteriormente mencionados, verificando-se a existência de diferenças, estatisticamente significativas, entre o aporte de ferro e fósforo nos indivíduos com e sem prótese $(p<0,05)$. Apesar dos indivíduos sem prótese apresentarem maior aporte de ferro, esse valor ultrapassa o recomendado em $0,8 \mathrm{~g}$, e os portadores de prótese apresentaram aporte de ferro recomendado para esta faixa etária. Tanto os portadores de prótese como os não portadores tinham excesso de aporte diário de fósforo, segundo as recomendações para esta faixa etária.

Compararam-se os resultados obtidos no presente estudo, relativamente ao aporte nutricional diário, com as DR/s (Dietary Reference Intakes), constatando-se que o aporte diário de proteína total, proteína de alto valor biológico, hidratos de carbono total, mono e dissacarídeos, niacina, vitamina B6, sódio e fosforo é superior ao recomendado tanto para os indivíduos portadores de prótese dentária tanto para os não portadores de prótese. Verificouse também que o aporte de fibra, ácido linoleico, vitamina A, D, B12, C, folatos, tocoferol, 
potássio, zinco, cálcio e magnésio encontram-se em défice comparativamente ao recomendado para esta faixa etária (Institute of Medicine Committe, 2011).

\section{CONCLUSÃO}

A saúde oral é uma parte integrante e fundamental da saúde geral da população geriátrica, sendo por isso um fator determinante na qualidade de vida. Existe frequentemente a falta de perceção quanto à necessidade de tratamentos odontológicos, tanto pelo próprio idoso como pelos seus familiares, refletindo-se numa falta de prevenção, informação e, consequentemente, cuidados de higiene oral precários, algo que tem de ser ultrapassado.

Com a elaboração deste estudo verificou-se, na análise estatística dos dados relativos ao aporte nutricional diário dos idosos, que existiram diferenças, estatisticamente significativas, relativamente ao aporte diário de ferro e fósforo, sendo que os idosos não portadores de prótese dentário apresentaram maior aporte destes micronutrientes, levando-nos a concluir que o uso de prótese dentária não influencia o aporte nutricional dos idosos, resultados estes em controvérsia com a literatura. Embora o uso de prótese não influencie o aporte nutricional, averiguou-se que tanto os indivíduos portadores como os não portadores deste tratamento de reabilitação apresentavam défices e excessos de alguns nutrientes comparativamente com o aporte diário recomendado para a população geriátrica.

Verificou-se que apenas o fator sociodemográfico - nível de escolaridade dos idosos, condiciona, com significância estatística, a periodicidade de visitas ao dentista, uma vez que à medida que aumenta a literacia do idoso, aumenta o número de vistas a este profissional de saúde. $O$ uso de prótese dentária está relacionado, com significância estatística, com o género e o nível de escolaridade, uma vez que o uso deste tratamento de reabilitação dentária é mais predominante no género feminino e que têm maior nível de escolaridade, regra geral, com o 10 ciclo. Constatou-se ainda, com significância estatística, correlação entre o tipo de prótese dentária e o rendimento dos idosos, uma vez que os portadores de prótese completa, prótese no maxilar inferior e implantes apresentam menor rendimento que os idosos com prótese no maxilar superior ou prótese parcial.

Como forma de responder a algumas questões com que nos deparámos durante este estudo e ultrapassar algumas limitações, sugere-se que sejam realizados mais estudos sobre este tema, integrando outras variáveis importantes como o motivo pelo qual os indivíduos não recorrem a tratamentos odontológicos, o estado da prótese dentária e a avaliação do estado nutricional dos idosos.

É necessário que haja formação de profissionais de saúde na área da odontogeriatria e o desenvolvimento de programas de prevenção, motivação e educação para a saúde oral, para que os idosos fiquem mais consciencializados para a necessidade contínua de tratamentos dentários, quer sejam dentados ou edêntulos. A otimização destas estratégias e a intervenção nutricional individualizada e personalizada para esta faixa etária seria um contributo para otimizar, não só a saúde oral, mas também, para a correção de défices nutricionais, aumentando a qualidade de vida, numa geração em que a longevidade é uma realidade, mas o recurso à hospitalização ou institucionalização são sistemáticos e no momento de admissão o risco de desnutrição é evidente, sendo a reabilitação clínica mais dificultada gerando elevados custos associados pela demora média de internamentos e pelos desperdícios alimentares agravando a desnutrição. 
Ao longo da recolha de dados, bem como na elaboração deste artigo, surgiram algumas limitações. Este estudo foi realizado numa amostra de conveniência, ou seja, uma amostra acessível aos investigadores, visto que não existe nenhuma região portuguesa que seja específica ou que abranja um maior número de idosos portadores de prótese dentária, representando também uma maior facilidade operacional e baixo custo de amostragem, contudo, é uma limitação, tendo como consequência a incapacidade de fazer afirmações gerais com rigor estatístico sobre a população. Outra limitação prende-se com a aplicação da ferramenta GOHAl, uma vez que as 12 questões tinham apenas duas respostas, "sim" ou "não", mas a forma correta, como está descrito na tradução da versão portuguesa desta ferramenta deveria ser "nunca", "às vezes" e "sempre" (Carvalho et al., 2013). Esta limitação decorreu de um erro das investigadoras ao elaborar o questionário de recolha de dados, sendo apenas possível verificar a existência de associação, estatisticamente significativa, de cada questão com o uso e tipo de prótese dentária, sendo impossível averiguar o índice GOHAI dos 400 idosos e, consequentemente, verificar qual a perceção do estado da saúde oral. Outra limitação prende-se com a comparação dos resultados obtidos no presente estudo com os encontrados na literatura, uma vez que são verificadas diferenças metodológicas, principalmente no que diz respeito à classificação dos tipos de prótese dentária, uma vez que em alguns estudos houve a colaboração de um profissional odontológico.

Atendendo a que não existe, em Portugal, nenhum estudo entre a associação do uso, tipo de prótese dentária e aporte nutricional da população geriátrica, considera-se este trabalho de investigação uma mais valia, uma vez que possibilita recolher dados sobre esta temática de três distritos portugueses, bem como identificar quais os aspetos que devem ser ainda explorados, para que no futuro haja dados concretos relativamente à implicação do estado da saúde oral dos idosos portugueses e suas implicações na alimentação e, subsequentemente, no estado nutricional dos mesmos.

\section{REFERÊNCIAS BIBLIOGRÁFICAS}

Agostinho ACMG, Campos CL, Cilveira JLGC. (2015). Edentulismo, uso de prótese e autoperceção de saúde bucal entre idosos. Revista de Odontologia da UNESP, 44(2):74-9.

Cardoso EM, Parente RCP, Vettore MV, Rebelo MAB. (2011). Condição de saúde bucal em idosos residentes no Município de Manaus, Amazonas: estimativas por sexo. Revista Brasileira de Epidemiologia, 14(1):131-40.

Carvalho C, Manso AC, Escoval A, Salvado F, Nunes C. (2013). Tradução e validação da Versão Portuguesa do Geriatric Oral Health Assessment Index (GOHAI). Revista Portuguesa de Saúde Pública, 31(2):166-72.

Correa SMBB. (2003). Probabilidade e Estatística. Pucminas, 2a ed.

Cunha JPM. (2013). Avaliação da Reabilitação protética numa amostra de idosos institucionalizados. Universidade Católica Portuguesa - Instituto de Ciências da Saúde.

Cunha M, Santos E, Costa A, Pereira M, Varanda R, Loureiro S. (2014). Saúde oral, Literacia e qualidade de vida em idosos - Revisão Sistemática da Literatura. Revista de Enfermagem Referência, 1:125-34.

Dias MRC. (2012). Saúde Oral e Alimentação numa População Geriátrica Márcia. Faculdade Medicina Dentária da Universidade do Porto, 1-27.

Diário da República. Portaria 3/2017 - Finanças e Trabalho, Solidariedade e Segurança Social. Diário da República. 2017;2-3. 
Ferreira CO, Antunes JLF, Andrade FB. (2013). Fatores associados à utilização dos serviços odontológicos por idosos brasileiros. Revista de Saúde Pública,47(3):90-7.

Goel k, Singh SV, Chand P, Rao J, Tripathi S, Kumar L, et al. (2016). Impact of different prosthodontic treatment modalities on nutritional parameters of elderly patients. Journal of Prosthodontics, 25(1):21-7.

Han SY, Kim CS. (2016). Does Denture-wearing status in edentulous south korean elderly persons affect their nutritional intakes. Gerodontology, 33(2):169-76.

Institute of Medicine (US) Committee. (2011). Dietary Reference Intakes (dris).

Instituto Nacional de Estatística (INE) (2017). Censos 2011. Consulta em outubro de 2017. Disponível em: http://censos.ine.pt/xportal/xmain?xpid=censos\&xpgid=censos_quadros.

Instituto Nacional de Estatística (INE). (2015). Envelhecimento da população residente em Portugal e na União Europeia. 1-8.

Kong H, West S. (2013) Declaração de Helsínquia da Associação Médica Mundial.

Lopes MFR. (2014). Próteses dentárias: removíveis flexíveis vs removíveis tradicionais. Universidade Fernando Pessoa.

Maroco J. (2003). Análise estatístico com utilizaçao do SPSS. Edições Silado. 2a ed

Mckenna G, Allen PF, Flynn A, O'mahony D, Damata C, Cronin M, et al. (2012). Impact of tooth replacement strategies on the nutritional status of partially-dentate elders. Gerodontology, 29(2):883-90.

Magalhães LRM. (2011). Relação entre saúde oral e nutrição em idosos. Universidade Fernando Pessoa.

Matos DL, Lima-Costa MF. (2007). Tendência na utilização de serviços odontológicos entre idosos brasileiros e fatores associados: um estudo baseado na pesquisa nacional por amostra de domicílios (1998 e 2003). Cadernos de Saúde Pública, 23(11):2740-8.

Müller F, Naharro M, Carlsson GE. (2007). What are the prevalence and incidence of tooth loss in the adult and elderly population in europe? Clinical oral implants, 18(3):2-14.

Oliveira AG. (2009). Bioestatística, Epidemiologia e Investigação. lidel. 2a ed.

OMS - Organização mundial de saúde. (2015). Relatório mundial de envelhecimento e saúde, 1:129.

Papalia D.E e Feldman R.D. (2013) Desenvolvimento humano. Porto Alegre. Artmed, 12aed.

Patrício M, Loureiro M, Caramelo F. (2015). Bioestatística com SPSS - abordagem prática. Plântano Editora. 1aed.

Pillai RS, Mathur VP, Jain V, Shah N, Kalra S, Kumar P, et al. (2015). Association between dental prosthesis need, nutritional status and quality of life of elderly subjects. Quality of life research, 24(12):2863-71.

Raosoft (2017). Sample size calculator. Consulta em outubro de 2017. Disponível em: http://www.raosoft.com/samplesize.html.

Sousa SIMD. (2016). Qualidade de vida relacionada com a saúde oral. Universidade de Coimbra, 4: 264-74.

Swain DG, Nightningale PG. (1997). Evaluation of a shortened version of the abbreviated mental test in a series of elderly patients, 243-8.

Toniazzo MP, Amorim PSA, Muniz FWMG, Weidlich P. (2018). Relationship of nutritional status and oral health in elderly: systematic review with meta-analysis. Clinical Nutrion, 37(3):824-30.

Vial C. (2017). Saúde oral numa sociedade em envelhecimento: importância da prevenção no idoso. Universidade Fernando Pessoa - Faculdade Ciências da Saúde. 
